\title{
Innovation management techniques and tools: a review from theory and practice
}

\section{Antonio Hidalgo and Jose Albors}

Department of Business Administration. Universidad Politécnica de Madrid, c/José Gutiérrez

Department of Business Administration. Universidad Politécnica de Valencia, c/Camino de

\begin{abstract}
Knowledge is considered to be an economic driver in today's economy. It has become a commodity, a resource that can be packed and transferred. The objective of this paper is to provide a comprehensive review of the scope, trends and major actors (firms, organizations, government, consultants, academia, etc.) in the development and use of methods to manage innovation in a knowledge-driven economy. The paper identifies the main innovation management techniques (IMTs) aiming at the improvement of firm competitiveness by means of knowledge management. It will specifically focus on those IMTs for which knowledge is a relevant part of the innovation process. The research study, based on a survey at the European level, concludes that a knowledge-driven economy affects the innovation process and approach. The traditional idea that innovation is based on research (technology-push theory) and interaction between firms and other actors has been replaced by the current social network theory of innovation, where knowledge plays a crucial role in fostering innovation. Simultaneously, organizations in both public and private sectors have launched initiatives to develop methodologies and tools to support business innovation management. Higher education establishments, business schools and consulting companies are developing innovative and adequate methodologies and tools, while public authorities are designing and setting up education and training schemes aimed at disseminating best practices among all kinds of businesses.
\end{abstract}

\section{Introduction: paper objectives}

Tnnovation is something of a buzzword. As 1 it is now perceived as central to achievement in the business climate of the 21 st century, organizations, large and small, have begun to re-evaluate their products, their services and their operations in an attempt to develop a culture of innovation. This re-examination of organizational purpose is due to the recognition that developing a culture of innovation within the organization is the best insurance an organi- zation can have of (relative) longevity in an environment of fast-moving markets. It is also the best guarantor, even though nothing is guaranteed, of long-term survival in today's knowledge-driven economy.

Various scholars from social and economy fields were pioneers in advancing the concept of a knowledge-based economy and predicting the decline of a manufacturing industrial culture (Clark, 1940; Young, 1961; Bell, 1974). New trends and types of data in the economy supported the idea of knowledge as a resource (Machlup, 1962). 
Subsequently, Drucker (1969) identified the concept of 'knowledge workers.'

Furthermore, the knowledge-driven economy is a recent idea based on the long evolution of previous concepts such as knowledge, the knowledge economy, etc. In the mid-1990s, the concept evolved to refer to, at least, two supposed characteristics of the new economy. Firstly, knowledge is more quantitatively and qualitatively important than ever before. Secondly, applications of information and communication technologies are the drivers of the new economy (Godin, 2003). The knowledge economy can be said to be based on an efficient system of distribution and access to knowledge as a sine qua non condition for increasing the amount of innovative opportunities (David and Foray, 1995). The OECD (1996) defines knowledge-based economies as 'economies which are directly based on the production, distribution and use of knowledge and information.' It is not simply about pushing back the frontiers of knowledge; it is also about the more effective use and exploitation of all types of knowledge within all manners of economic activity.

In this direction, two schools of thought have developed (Dankbaar, 2003) linking knowledge and innovation management: that of Drucker, already mentioned, which, following Taylor, suggests that innovation management involves the application of knowledge to the work of knowledge workers within a clear and defined context, and, alternatively, that of Burns and Stalker (1961), which outlines a context of more blurred organic and flexible structures that foster creativity by limiting bureaucracy.

The increasing importance of knowledge is changing the way firms compete and the sources of comparative advantage between countries. For countries in the forefront of the world economy, it is a reality that the balance between knowledge and tangible resources has shifted so far toward the former and that knowledge has become perhaps the most important factor determining the standard of living (World Bank, 1998). Today's most technologically advanced economies are truly knowledge-based. The main changes associated with the importance of knowledge as an economic driver in today's economies are:

- Knowledge is increasingly considered to be a commodity. It is packaged, bought and sold in ways and to levels never seen before.

- Advances in Information and Communication Technologies (ICTs) have reduced the cost of many aspects of knowledge activity, for exam- ple, knowledge gathering and knowledge transfer.

- The degree of connectivity between knowledge agents has increased dramatically.

This paper has three major objectives:

1. To provide a comprehensive review of the scope, characteristics, trends and business relevance of the main innovation management methodologies developed by relevant actors in this field (those that seek to provide advice to firms, and that focus on knowledge as the most important benefit to a firm) across the European Union, the United States and Japan.

2. To clarify and facilitate both a conceptual framework in this area and a consensus among the relevant actors developing and using these methodologies.

3. To analyze the perceptions of various key players - the promoters and users of such methodologies.

The paper is organized as follows: First, innovation management has been reviewed from a conceptual knowledge framework, paying special attention to the challenges of the knowledge-driven economy context. Second, innovation management techniques and tools are introduced and a taxonomy is proposed. Third, the results of the survey are discussed. Finally, the last section concludes by outlining the conclusions of the research.

\section{Knowledge and innovation management: innovation techniques}

\subsection{What is innovation?}

The first and seminal definition of innovation was proposed by Schumpeter (1934). He associated it to economic development and defined it as a new combination of productive resources. His work defined five specific cases: introduction of new products, new production methods, exploration of new markets, conquering of new sources of supply and new ways of organizing business.

Since then, the conception of innovation has evolved significantly over the last 40 years. During the 1950 s, innovation was considered to be a discrete development resulting from studies carried out by isolated researchers. Nowadays, innovation is no longer conceived as a specific result of individual actions, but more as the following:

- A process, more specifically, a problem-solving process (Dosi, 1982). 
- An interactive process involving relationships between firms with different actors (Kline and Rosenberg, 1986).

- A diversified learning process. Learning may arise from different issues: learning-by-using, learning-by-doing or learning-by-sharing, internal or external sources of knowledge and the absorption capacity of firms (Cohen and Levinthal, 1990; Dogson, 1991).

- A process involving the exchange of codified and tacit knowledge (Patel and Pavitt, 1994).

- An interactive process of learning and exchange where interdependence between actors generates an innovative system or an innovation cluster (Edquist, 1997).

Other authors (Rogers, 1983; Urabe, 1988; Utterback, 1994; Afuah, 1998; Garcia and Calantone, 2002; Mc Dermott and O'Connor, 2002; Pedersen and Dalum, 2004, etc.) have outlined other aspects of innovation more related to the final consumer of innovative goods or services as well as to the innovation process. Finally, the latest editions of the Oslo (2005) and the Frascati Manual (2004) have brought into consideration a holistic view of innovation.

The evolution from a technological network perspective of innovation management to a social network perspective (Rogers, 1983, Ahuja, 2000) has been led by the challenge to transform information into knowledge (e.g. information contextually connected to the development or improvement of products or processes). Knowledge-based innovation requires not one but many kinds of knowledge. Furthermore, it requires the convergence of many different kinds of knowledge retained by a variety of actors.

From a strategic point of view (Schlegelmilch et al., 2003), innovation is driven in two different ways: internally and externally. From an internal perspective, innovation is driven by senior management attitudes, marketing, information technology departments and the organization's employees. Collaborative efforts support and facilitate the innovation management process. These are evidenced by:

- Senior management teams that devote time to investigate the future and to understand the needs of the marketplace, the resources at their disposal and the competitive business environment.

- Working environments and organizational culture that encourage creative solutions.
- Strong support for joint ventures and collaborative efforts that develop and commercialize innovative solutions.

- Good project management for the identification, development and commercialization of innovations.

From an external perspective, innovation management is driven by different knowledge-intensive organizations (KIOs) that build knowledge as their primary value-adding process. They can be defined as organizations where employees with a high degree of knowledge are critical to the primary function of the organization. They have relatively little financial capital but instead have as main assets the knowledge and competence of their personnel (Kipping and Engwall, 2002). Such organizations are also characterized by having core activities that cannot be automated, material assets that are not a central factor, critical assets (intellectual capital) residing in the minds of employees and in networks and customer relationships and systems for supplying services. In addition, there is a heavy dependence on the loyalty of key personnel, a tendency to measure success not solely by financial criteria and a balance sheet value that differs strongly from real organizational or customer value. ${ }^{1}$

The seminal work of Utterback (1994) and Tushman et al (1997) has analyzed how external environment affects business organizational $\mathrm{dy}$ namics and strategic change. Von Hippel (1988, 2005) has analyzed the increasing role of users in innovation diffusion processes and its impact on product development. Although it goes farther, the latter could be inscribed with the open innovation model proposed by Chesbrough (2003).

\subsection{Impact of knowledge on innovation management}

The increasing importance of knowledge as an economic driver has major implications for innovation management, which is, in turn, a key determinant of national and regional competitiveness in the global, knowledge-driven economy. The contribution of knowledge to innovation is achieved in part by reducing transaction costs between firms and other actors, most notably in the areas of research and information, buying and decision-making as well as innovation policy and enforcement (Maskell, 1999).

The systemic approach to innovation recognizes that innovation and knowledge generation take place as a result of a variety of activities, 
many of them outside the formal research process (Liyanage and Poon, 2002). Knowledge is thus generated not just in universities and research centers but also in a very wide variety of locations within the economy, and notably as a product (learning-by-doing) or of consumption (learningby-using). In the current economic context, growth must mainly originate from increasing the productivity of knowledge work, and increasing this productivity is the most important contribution management can make. The most valuable assets of a 21 st-century firm are its knowledge workers and their productivity. KIOs, ranging from knowledge-intensive serviceproviders to high-tech manufacturers, need to manage innovation processes so as to increase knowledge productivity (Drucker et al., 1997).

Innovation and knowledge generation have been analyzed by Popadiuk and Choo (2006) from a specific systemic approach considering the market role, the knowledge architecture, etc. and the innovation alternatives (process, product, radical, incremental) outlining a parallel comparison between both processes (knowledge and innovation).

In comparison with traditional mechanistic command and control management, innovation management entails a fundamental change in the strategic perception of the organization, which accordingly has to consider the following management challenges:

- Manage human capabilities in a strategic manner. Modern management has to face the perpetual challenge to place the human being at the forefront of operations, and understand that an organization is a collection of different human beings (James, 2002).

- Network with internal and external partners. People have different attitudes, different customs, different professional backgrounds management should focus on integrating the web of formal and informal relationships inside and outside the company (Ahuja, 2000).

- Create adaptive and interactive organizational structures. If the organization is to remain responsive to external change, a flexible and adaptable organizational structure is a necessity (Schlegelmilch et al., 2003).

- Balance order and chaos - process efficiency versus destructive innovation - and individual and corporate motivation by developing an innovation strategic vision (Martensen and Dahlgaard, 1999).
The challenges of the new knowledge-driven economy can be classified into the following groups:

- New characteristics of the market. The market is constantly changing, it is becoming more global and new competitors are emerging. In addition, technology complexity is increasing, product life-cycles are shortening and knowledge is consolidating as a crucial input. All of these new characteristics of the market require the development of additional competitiveness from firms.

- New types of innovation. Innovation takes many forms. There is technological innovation, but also innovation through new business models and new ways of organizing work, innovation in design and in marketing. Innovation can also consist of finding new uses and new markets for existing products and services. It emerges where the market offers incentives to introduce new products and production methods, and where people are willing to take risks and experiment with new ideas (Bullinger et al., 2004).

- New needs of stakeholders. Customers, owners and stock markets increasingly equate an organization's worth with its ability to get winning products to market on time, every time. This is especially true in the case of SMEs (Libutti, 2000; Scozzi and Garavelli, 2005).

- New approach to innovation management. Innovation management encompasses all the key areas that need to be mastered to develop successful products and services, efficiently and continuously. The capacity of a firm to implement innovation management revolves around its success in dealing with these two main challenges: top-line growth and bottomline efficiency (Liyanage and Poon, 2002).

- New technology innovation assessment skills. The rapid development of new technologies prompts firms to assess and implement the most appropriate technology according to their need to retain their competitiveness (Ram, 1996).

- Need for new innovation management tools. The development of knowledge-based innovation management requires the capacity to implement technical and relational tools. Technical tools refer to the acquisition and utilization of new information and communication technologies - they do not create a competitive advantage because they are readily available to others. The creation of 
competitive advantage rests in relational tools - the way of doing business, both in the internal and the external environments of firms (Lengrand and Chartrie, 1999). Moreover, technology and innovation require a holistic approach today (Butler, 1999; Martensen and Dahlgaard, 1999).

\subsection{IMTs}

Taking into account the previous considerations, innovation management has been associated with knowledge management (Coombs and Hull, 1998). Coombs et al. (1998) define 'Knowledge Management Practices for Innovation' as those '... observable routines involved directly in the development and application of knowledge.' The previous authors have identified these tools by observing the practices of numerous $\mathrm{R} \& \mathrm{D}$ firm departments. It is from this basis that innovation management has been approached in a holistic way. Freeman and Soete (1997) include in the innovation process all those activities encouraging the commercialization of new technologies. Moreover, Dogson (2000) proposes a holistic model that includes six specific areas in the management of technology innovation: $R \& D$, new product development, commercialization of innovation, operations and production, technological collaboration and technology strategy. $\mathrm{He}$ points out that the context of Management of Technology Innovation is complex (of systemic nature) and risky. There are problems associated with uncertainty, knowledge appropiability and costs unpredictability. As a consequence, firms trying to develop organizational competitiveness in innovation will require knowledge management and organizational skills in order to learn fast (see enclosed Figure 1).

Innovation does not always mean using the very latest cutting-edge technology. On the contrary, it is less a question of technology and more a way of thinking and finding creative solutions within the company. In this context, IMTs can be seen as a range of tools, techniques and methodologies that help companies to adapt to circumstances and meet market challenges in a systematic way (Phaal et al., 2006). The growth of IMTs results from a new way of thinking. It is not necessarily due to technology, but more to the capacity of firms to apply their knowledge to improve their businesses internally and their relationships with external actors. This is true for both large and small firms, as innovation is vital

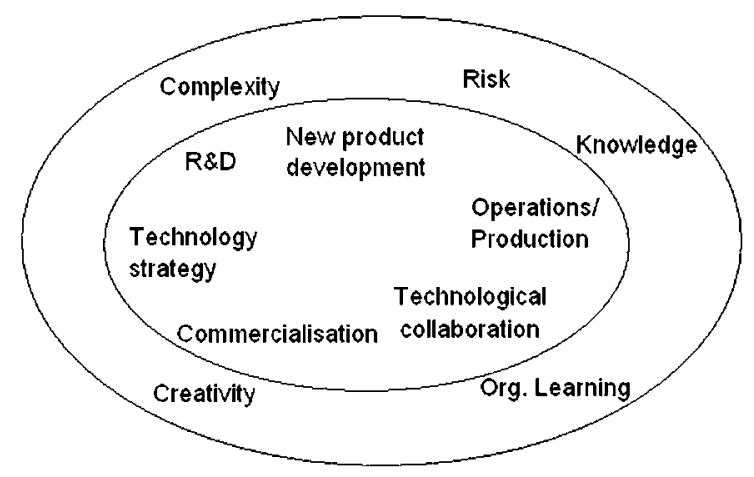

Figure 1. Management of technological innovation: a holistic approach (Dogson, 2000).

to the survival of both in a competitive, changing marketplace.

In innovation management, there is a wide range of IMTs available on the market. This study focused on IMTs that complied with the following parameters:

1. IMTs that were sufficiently developed and standardized, and had fairly systematic methods of application. In other words, the implementation procedures and the benefits for the IMT were generally known and recognized in the market.

2. IMTs that aimed to improve the competitiveness of firms by focusing on knowledge as the most important benefit. Companies make use of a variety of tools and techniques to perform their daily management. This study considered only IMTs that include knowledge as part of the innovation process.

3. IMTs that were freely accessible on the market and not subject to any copyright or licensing agreement.

The application of a group of selection criteria resulted in 10 groups of IMTs called 'IMT typologies.' Table 1 summarizes the 10 IMT typologies and their associated methodologies/tools.

There is no one-to-one correlation between one firm's specific business problem and the methodology that solves it. As a result, it cannot be claimed that there is a closed set of developed and proven IMTs for solving, one by one, the challenges faced by business as a whole. Furthermore, IMTs do not usually act in a deterministic, unique manner and the diversity of firms and business circumstances means that there is not a single ideal model for innovation management, although there are some principles of good practice. 
Table 1. IMT typologies and associated methodologies ${ }^{1}$

\begin{tabular}{|c|c|}
\hline IMT typologies & Methodologies and tools \\
\hline $\begin{array}{l}\text { Knowledge } \\
\text { management tools }\end{array}$ & $\begin{array}{l}\text { Knowledge audits } \\
\text { Knowledge mapping } \\
\text { Document Management } \\
\text { IPR Management }\end{array}$ \\
\hline $\begin{array}{l}\text { Market intelligence } \\
\text { techniques }\end{array}$ & $\begin{array}{l}\text { Technology Watch/ } \\
\text { Technology Search } \\
\text { Patents Analysis } \\
\text { Business Intelligence } \\
\text { CRM: Customer relationship } \\
\text { management } \\
\text { Geo-marketing }\end{array}$ \\
\hline $\begin{array}{l}\text { Cooperative and } \\
\text { networking tools }\end{array}$ & $\begin{array}{l}\text { Groupware } \\
\text { Team-building } \\
\text { Supply Chain Management } \\
\text { Industrial Clustering }\end{array}$ \\
\hline $\begin{array}{l}\text { Human resources } \\
\text { management } \\
\text { techniques }\end{array}$ & $\begin{array}{l}\text { Teleworking } \\
\text { Corporate intranets } \\
\text { On-line recruitment } \\
\text { e-Learning } \\
\text { Competence Management }\end{array}$ \\
\hline $\begin{array}{l}\text { Interface } \\
\text { management } \\
\text { approaches }\end{array}$ & $\begin{array}{l}\text { R\&D - Marketing Interface } \\
\text { Management } \\
\text { Concurrent Engineering }\end{array}$ \\
\hline $\begin{array}{l}\text { Creativity } \\
\text { development } \\
\text { techniques }\end{array}$ & $\begin{array}{l}\text { Brainstorming } \\
\text { Lateral Thinking } \\
\text { TRIZ } \\
\text { Scamper Method } \\
\text { Mind Mapping }\end{array}$ \\
\hline $\begin{array}{l}\text { Process improvement } \\
\text { techniques }\end{array}$ & $\begin{array}{l}\text { Benchmarking } \\
\text { Workflow } \\
\text { Business process re-engineering } \\
\text { Just in Time }\end{array}$ \\
\hline $\begin{array}{l}\text { Innovation project } \\
\text { management } \\
\text { techniques }\end{array}$ & $\begin{array}{l}\text { Project management } \\
\text { Project appraisal } \\
\text { Project portfolio management }\end{array}$ \\
\hline $\begin{array}{l}\text { Design and product } \\
\text { development } \\
\text { management tools }\end{array}$ & $\begin{array}{l}\text { CAD systems } \\
\text { Rapid Prototyping } \\
\text { Usability approaches } \\
\text { Quality Function Deployment } \\
\text { Value analysis }\end{array}$ \\
\hline $\begin{array}{l}\text { Business creation } \\
\text { tools }\end{array}$ & $\begin{array}{l}\text { Business Simulation } \\
\text { Business Plan } \\
\text { Spin-off from research to } \\
\text { market }\end{array}$ \\
\hline
\end{tabular}

${ }^{1}$ Developed by authors based on various sources (Thom, 1990; Cordero, 1991; European Commission, 1996; Ram, 1996; Libutti, 2000; European Commission, 2005; Scozzi and Garavelli 2005; Phaal et al., 2006).

For these reasons, an innovation management technique cannot be considered in isolation. The usefulness of one IMT for a particular business challenge is normally measured in combination with other IMTs, this combination being adapted to varying degrees for each specific case. The benefit gained by the company depends on a combination of IMTs and the firm itself, and the mix of these two elements is what determines an effective outcome. To achieve the best fit between an IMT and the company, an understanding is needed of the firm and its business. This understanding is necessary to support the definition of clear objectives, and the criteria for knowing when those objectives have been achieved. The criteria can be framed in terms of survival, growth, new product introduction, competitiveness, etc.

\section{Methodology: field work}

The methodology followed in this research is based both on an exhaustive literature research and a survey carried out of a balanced sample (geographically and activity wise) of firms, academic centers, business schools, consulting firms, business support organizations (BSOs) and government agencies.

The research was financed by the European Commission and was carried out among respondents from the 15 Member States of the European Union. In total, 4,000 questionnaires were distributed. The target audience was defined as follows: $50 \%$ from industry and $50 \%$ distributed across four categories: consultancies, business schools, academic centers and BSOs. Questionnaires were available in four languages: English, French, Spanish and German. To facilitate both the collation and analysis of questionnaire responses, survey participants were mostly requested to select their answers from a closed list. Some questions, however, were open-ended so that participants were able to describe some of their suggestions and experiences on the implementation of IMTs. The questionnaire was tested before launch of the questionnaire to the target audience with a pilot audience sample.

The choice of the number of organizations from each country to send the questionnaire was determined according to the following factors: population of each EU Member State and economic weight, measured by the GDP. However, there was a bias to these conditions, simply because the degree of innovation culture and development of IMTs within a country has no direct relationship with its size. This unavoidable bias was carefully reviewed to take into consideration the qualitative aspects related to the object of the study. Additional factors were then introduced, such as policies recently developed, priority given to IMTs by universities and business schools, etc. The resulting selection of target sample represented in the opinion of the study 


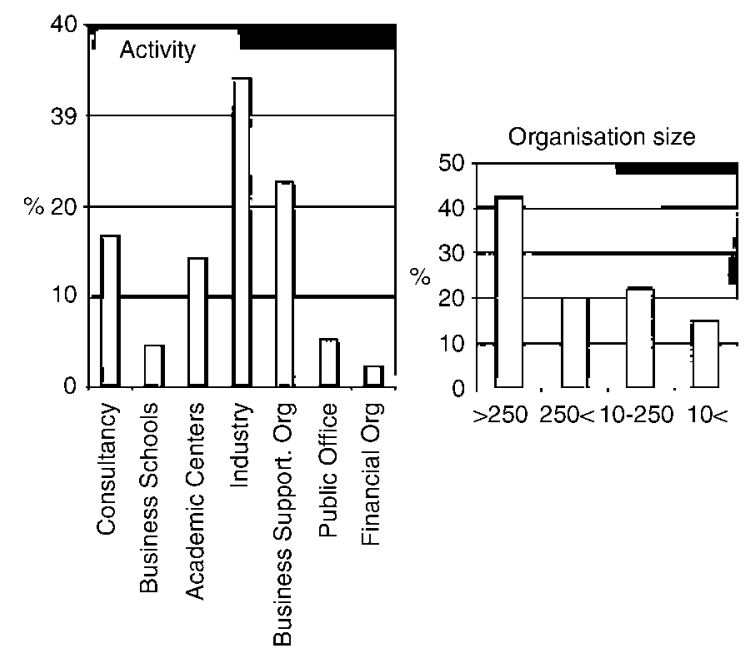

Figure 2. Sample characteristics.

participants a fair cross-section of European industries and institutions involved in IMTs, in proportion to country size, with respect to population, GDP and degree of innovation.

The results were 426 completed questionnaires returned. The information collected from the survey was completed via phone interviews with the most representative stakeholders, which went into more detail on certain issues of relevance for the study and clarified some outstanding questions. ${ }^{2}$

Figure 2 shows the characteristics and composition of the sample in size as well as the type of participating organizations.

The questionnaire was structured in four basic areas. In the first, the participant described its organization, type and size. In the second, its perception and experience with IMTs. The third part was dedicated to the roles to be played by actors with IMTs and the challenges posed by the knowledge economy. The last part was dedicated to evaluate the needs related to competitiveness that could be met by IMTs. Except for a couple of questions the questionnaire was composed of closed questions, to be answered through Likertscale replies.

\section{Results: key perceptions from the leading actors and business relevance of IMTs}

\subsection{Role of each actor in innovation management and roles of IMTS promoters}

For the purpose of this study, 'major actors' were defined as those bodies that play an important

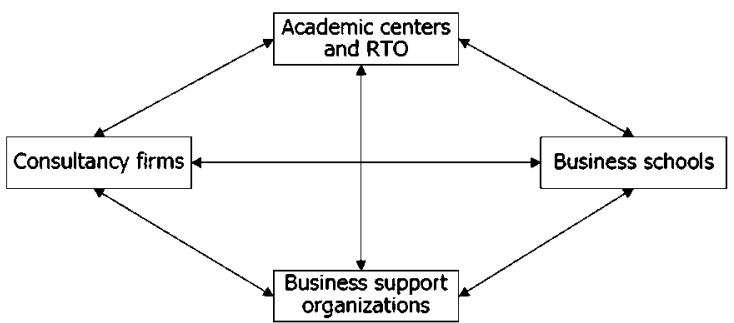

Figure 3. The knowledge management industry.

role in the development and/or promotion of methodologies to support innovation management in the knowledge-driven economy. This definition of major actors is closely linked to the final product delivered by the firms involved. In defining the major actors in the knowledge-driven economy, we consider that knowledge management and/or knowledge is the main product sold or disseminated by these actors. These actors were classified into four groups: business schools, consultancies, academic centers and research and technology organizations (RTOs) and BSOs.

Such agents play an important role in the knowledge management industry. They also interact with each other e.g. consultancy firms cooperate with academic institutions and business schools in the creation of management practice. Figure 3 shows the relationship between such actors.

The roles of the different actors and the relationships between them vary from country to country. In some regions such as the Nordic countries, management education has a long history and a large number of management graduates are active in practice, consultancies and other companies. In other countries, France and Germany for example, education plays a stronger role in linking together actors in the different fields of management. It is also worth highlighting that the socioeconomic context is crucial to understanding the development of the knowledge management industry. Highly industrialized countries with a large number of multinational corporations, particularly with a high degree of internationalization, are more likely to exhibit an expansion of actors than those nations with a lesser degree of industrialization and those with larger numbers of small companies.

The study produced the following overall views on the roles of the major actors:

Academic centers, including RTOs, are promoters of IMTs and, in some specific cases, developers of them. In that case, they only adapt specific tools for SMEs. Their capacity to develop IMTs is concentrated sometimes in the 
development of strategies to raise the level of R\&D activity among local or regional governments and some evaluation of R\&D public programs. One example might be the definition and implementation of a structured tool deployment for an R\&D department, in order to evaluate the strategic optimization of the R\&D outputs and, at the same time, the awareness and monitoring of the intellectual property rights (IPRs) and unique selling positions of their R\&D activities.

Business schools consider themselves as developers and promoters of IMTs. From the development perspective, it is the academic specialists with a high research orientation and high specialization who integrate business schools, because many of them develop part of their research activity directly in academic centers and combine academic and research work with consulting activities. The academic work carried out, for example in the form of doctoral dissertations, has the effect of transforming their unique competence into common knowledge. As promoters business schools use several tools. However, they mostly do not classify them into a defined sequence of employment. The most interesting mechanisms used to disseminate methodologies are the organization of seminars and workshops.

Consultancy firms consider themselves more as developers than promoters of IMTs and, for that reason, some of them in Europe were founded in order to support the regional economy or to diversify national economic activities. Most of the consultancies' activities in relation to IMTs have to do with technology transfer i.e. to transfer results from R\&D to SMEs (high-technology companies, start-ups, etc). Some individual consultancy firms stressed the importance of motivation. These firms considered it one of their main objectives to motivate people to run their business, and to motivate SMEs to diversify activities in view of European Union enlargement. The use of IMTs was identified as a growth area currently under-serviced.

BSOs consider themselves as promoters and users of IMTs: they make available some tools to the SME members of their organization, for example, the wider use of benchmarking and related methodologies in entrepreneurship. They also act as a link between SMEs and innovation consultants and try to encourage the use of IMTs among third-party organizations (other BSOs). For example, coaching a network to develop innovative ideas and transform them into solid business plans. BSOs also consider themselves as developers of IMTs, but only when adapting
IMTs in cooperation with consultants. In this case, IMT represents a tool for assisting firms to evaluate market opportunities and to assess the value of investments, to identify gaps, strengths and weaknesses and to formalize a strategy.

Finally, the opinion of managers within the companies was that consultancies are the main actors promoting the use of IMTs $(27 \%)$, jointly with business schools (20\%), and BSOs (20\%). With respect to helping firms use IMTs, consultancies are seen as the major agents $(41 \%)$, while business schools $(16 \%)$ and BSOs $(15 \%)$ have less importance. The companies themselves consider their role to be more as users than developers of such methodologies.

Actors agree that the effect of their 'consultancy work' is very difficult to evaluate. First of all, the consultancy intervention is only one factor, and probably not even the most important one, determining the performance of firms, making it difficult to isolate its impact. Second, the intervention itself destroys any base for comparison, making it impossible to see how the firm would have done if it had not called in consultants.

All the major actors agree that only a few IMTs are widely recognized, and most are unidentifiable and inaccessible by firms. Over $37 \%$ of the actors declared that most firms are not aware of the existence of IMTs, while $34 \%$ stated that few IMTs are sufficiently defined to be successfully applied within firms.

Consultancy firms and business schools generally believe that most firms are not aware of the existence of IMTs. Academic centers and industry generally see IMTs as systematically applied only in firms that want to be market leaders. BSOs mostly believe that very few IMTs are defined sufficiently well to be successfully applied within firms. All actors are convinced that new challenges coming from the knowledge-driven economy require new IMTs (Figure 4).

\subsection{The companies' perspective}

The process of innovation management is something that can be built into the culture of a firm. It can be promoted by using specialized techniques, and building a prevailing atmosphere of encouragement for new ideas. The goal is to change the firm, to achieve a metamorphosis from a group of people doing a job to a highly energized team that is constantly searching for new and better ways of making the vision a reality. The experience of many European firms provides an interesting 


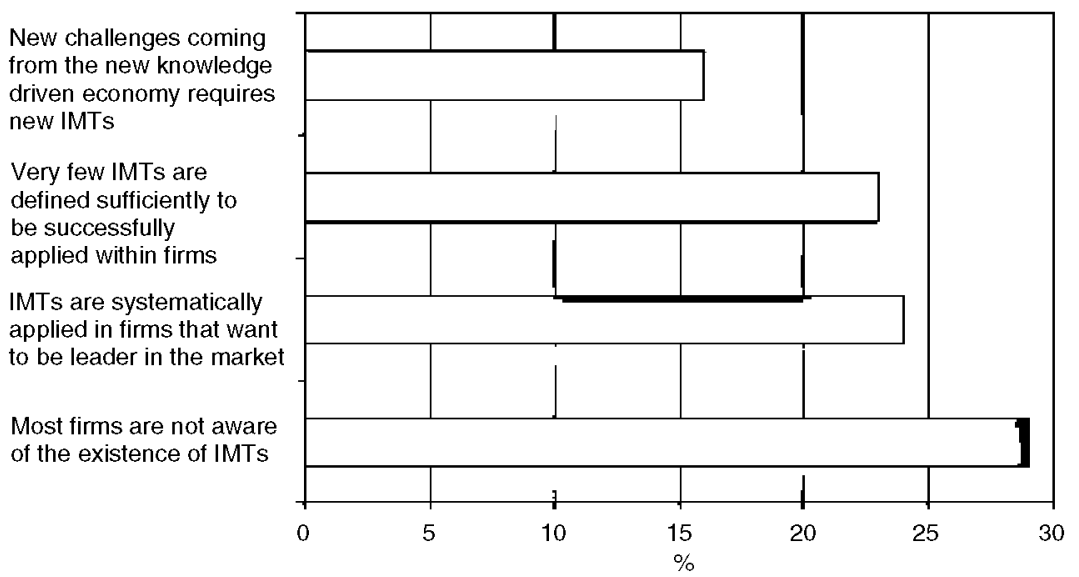

Figure 4. Opinion over innovation management techniques (all actors included).

insight into strengths and needs in innovation, investments into innovation and the output achieved, and cooperation and the sharing of knowledge in practice. In the main, the evidence showed that:

- The share of new or renewed products or services introduced within the last 2 years accounted on average for $22 \%$ of firms' turnover. In general, two companies out of three introduced new products or services over the last 2 years.

- Innovative efforts focus evenly on organizational changes, new products and new processes; there is a clear interdependence in the top priorities of managers, confirming that they perceive innovation more as an overall strategy than as specific, independent improvements.

- Business leaders are aware of the importance of innovation for their company and are confident in their performance.

- Cooperative agreements are an important tool to launch new products or services or to introduce new processes, and more executives are keen on sharing their knowledge and/or resources through such agreements.

- New approaches to the management of innovation will focus in particular on the relationship with suppliers and users.

Many companies feel that more effort is needed to motivate staff at all levels to acquire new competencies and to adapt to changes. At the same time, managers attribute their strength in innovation in the first place to the qualification and professionalism of their staff. The next most important strengths are seen as good cooperation with suppliers, customers or trade associations and the flexibility and adaptability of production to market needs. Exceptionally, basic skills are also identified as requiring improvement.

The industrial responses placed great emphasis on how important it is to change attitudes, and also how difficult this can be. The hierarchy within a company can hinder innovation, with some staff believing that innovation is a senior management responsibility. Reservations about the economy also restrict innovation because staff is constantly afraid of redundancy. This makes them less likely to take risks or put themselves in a position where they are associated with a project that might fail. Encouraging staff to share their acquired knowledge within the firm is a major challenge, and possibly one that can be encouraged within the knowledge-driven economy by the application of technology-based tools to support this process.

\subsection{Difficulties and challenges in facing the knowledge-driven economy}

Many of those involved in promoting better innovation management expressed their opinion about the difficulties and challenges facing companies. The main difficulties seemed to revolve around the fact that introducing an IMT within an organization means an extra effort that requires time, motivation and money. The challenge is to motivate management support, to think of the future and foster creativity, to install a culture of innovation, to formulate an innovation strategy and to implement the innovation process.

IMTs are sometimes considered to have a more academic than practical role, because they are subject to a lack of awareness and motivation, 
and consequently a widespread ignorance about how IMTs can help companies to survive in the new knowledge-driven economy. On the other hand, many actors stressed the lack of an innovative culture in firms, as well as the uncertainty in predicting the conditions for competitive performance in new markets. Another difficulty is that innovation management cannot be handled as product or as production management. The reason is that many firms do not have the capacity to identify innovations and introduce them into the normal production process. Further difficulties include: bureaucratic complexity, low awareness of innovation technology amongst managers, lack of suitable metrics, and unwillingness to share knowledge.

From the challenges point of view, actors highlighted four specific areas as presenting the greatest obstacles:

- Financial investment needed. Difficulties in obtaining finance applied both to access to public funding and internally, where firms may be short of cash to invest in new product development.

- Difficulty of accepting failure. Acceptance of failure is a natural part of the innovation process. Yet few managers wish to be associated with failed projects, as it damages their profile in the company. Firms discourage failure as it reflects on the decision-making process within the company and on the participants who made the decision to carry a project forward.

- Excessive bureaucracy and uncertainty also need to be overcome, by shaping policies and legislation that encourage innovation and reduce bureaucratic administration procedures (both locally as globally) that hinder the innovation process itself, especially when public authorities are trying to finance initiatives.

- Finally, actors underlined the need to support training schemes and to overcome intercultural complications, particularly when knowledge sharing is necessary.

\subsection{Business relevance of IMTS}

4.4.1. How to measure the business relevance In the knowledge economy, products and companies live or die by information - the most successful companies are those that use their intangible assets better and faster. Corporate reporting is still founded on a financial and management accounting model. This model was developed for the industrial economy and is not able to deal with today's knowledge economy, where most corporate value creation is based on knowledge assets rather than on physical resources and financial capital.

IMTs applied in business have to be able to manage change and take into account the challenge of the new knowledge economy. It is always useful to be able to measure the impact that the implementation of IMTs has within companies. However, it is extremely difficult to create any measure of knowledge that will show an absolute one-to-one correlation between a knowledge sharing action and a business result. Many senior managers understand that sharing knowledge and re-using experience are simply good business sense.

For the purposes of this study, and as a means of quantifying the business relevance of the different IMTs, the survey questionnaire detailed a list of benefits for the IMTs that respondents were invited to evaluate. The list of benefits is as follows:

- Increasing flexibility and efficiency.

- Managing knowledge effectively.

- Increasing productivity and reducing time to market.

- Facilitating teamwork.

- Enabling online gathering of marketing information.

- Improving relationships with suppliers.

- Integrating differing sources of customer information.

- Making client relationships more effective.

- Eliminating redundant processes.

- Reducing costs by implementing IT-based solutions.

- Reducing bureaucratic tasks (those that did not add value).

- Using e-learning.

- Exploring e-commerce.

- Increasing the market range of goods and services.

- Improving relationships with employees.

4.4.2. Business impact according to the major actors The business schools' point of view is that the main advantages that IMTs give firms are increased flexibility and efficiency, an understanding of how to use e-learning, facilitated teamwork, improved gathering of on-line marketing information, and integration of the different sources of customer information (Figure 5). 


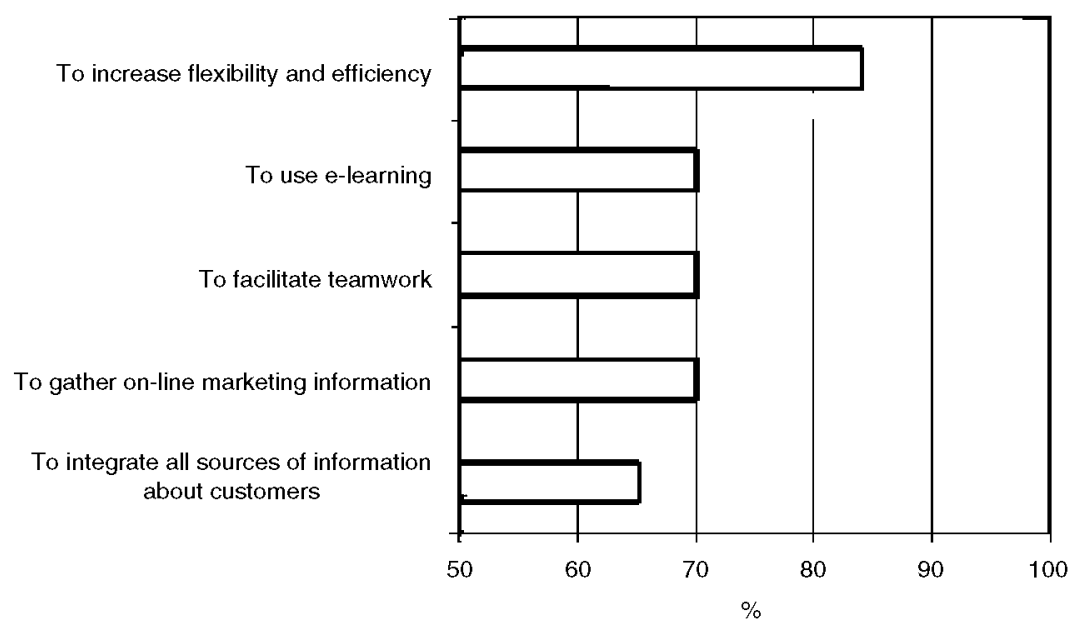

Figure 5. Innovation management techniques relevance for business schools.

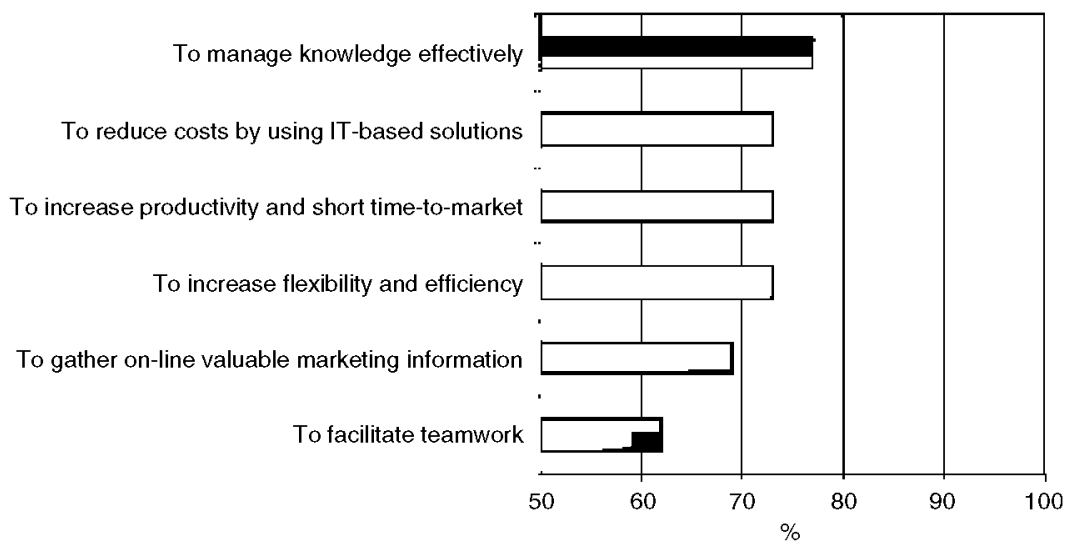

Figure 6. Innovation management techniques relevance for academic centers.

Business schools apply creativity development, business plan development, e-learning techniques and customer relationship management (CRM) internally.

From the perspective of the academic centers, IMT benefits tend to be in the areas of managing knowledge effectively, reducing costs by using IT-based solutions, increased productivity and shorter time-to-market, increased flexibility and efficiency, better gathering of on-line market information, and improved teamwork (Figure 6). Project management, corporate intranet, spin-off and e-learning techniques are the IMTs most successfully applied by the academic centers and RTOs.

Consultancy firms tend to the view that the most important benefits are managing knowledge effectively, increased flexibility and efficiency, facilitating teamwork, reduced bureaucratic tasks, increased productivity, improved relationships with suppliers, and making relationships with customers more effective (Figure 7). Consultancies consider business plan development, project management, corporate intranet and benchmarking as the IMTs most used within their organizations.

From the perspective of BSOs, IMTs serve mainly to increase flexibility and efficiency, increase productivity and reduce time-to-market, gather on-line marketing information, manage knowledge effectively, and increase the effectiveness of relationships with suppliers (Figure 8). BSOs are more oriented toward project management, corporate intranets, business plan development and outsourcing.

\subsubsection{IMTs business impact in firms}

Within the firms that actually implement IMTs, the perspective of the managers involved is that IMTs can help their firms to foster competitive advantages in the following ways: 


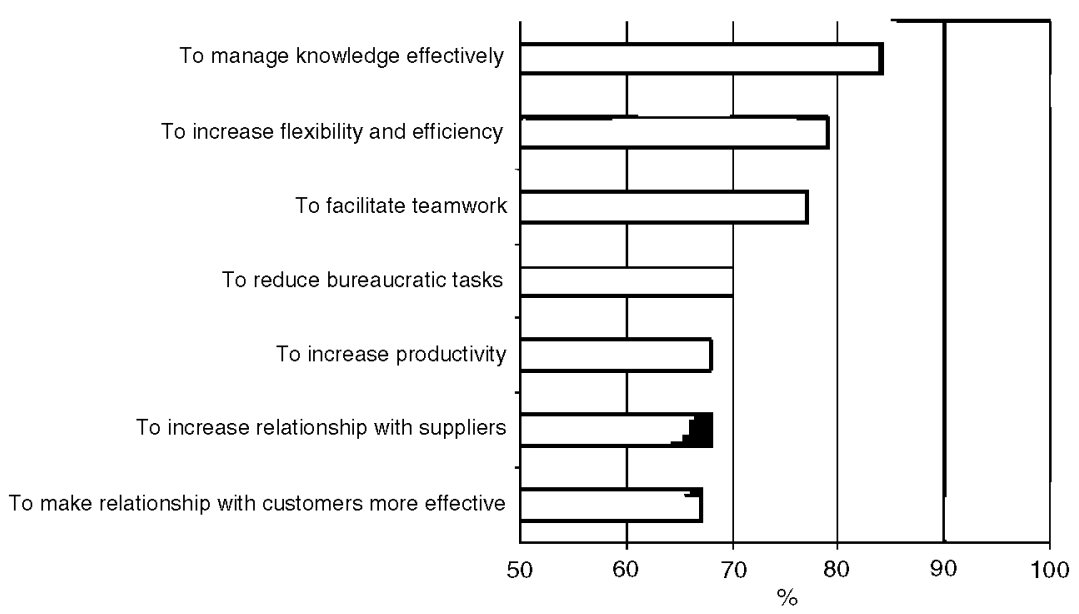

Figure 7. Innovation management techniques relevance for consultancy firms.

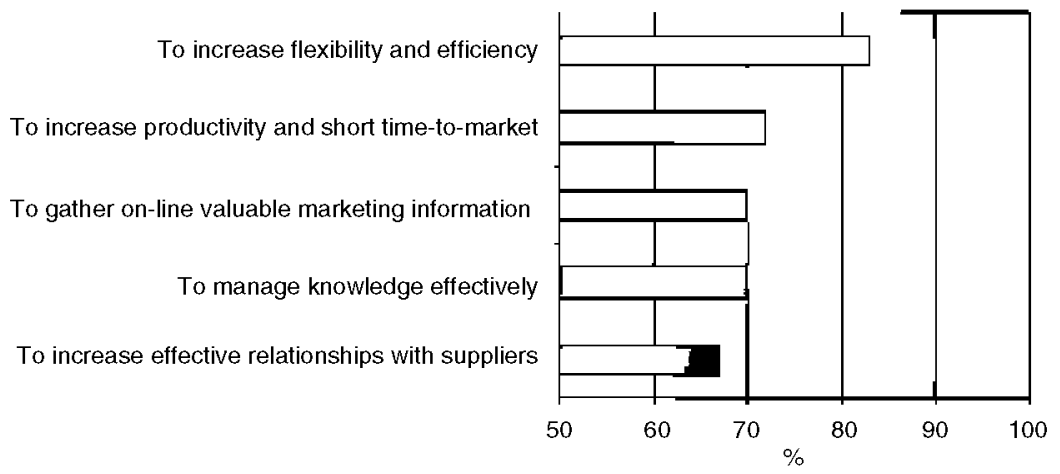

Figure 8. Innovation management techniques relevance for business support organizations (BSOs).

- Increasing flexibility and efficiency $(86 \%)$.

- Managing knowledge effectively $(76 \%)$.

- Improving productivity and time-to-market $(73 \%)$.

- Improving relationships with suppliers $(72 \%)$.

- Gathering on-line marketing information $(69 \%)$.

- Facilitating teamwork $(67 \%)$.

- Integrating different sources of customer information $(66 \%)$.

- Reducing costs by using IT-based solutions $(65 \%)$.

- Eliminating redundant processes $(64 \%)$.

Companies tend to focus especially on techniques in the areas of project management, business plan development, outsourcing and benchmarking.

Innovation is seen as a key business opportunity for many consultancies and industrial partners, but not for all of them. For some managers, IMTs do not seem to be central to their business concerns. Rather, their major issues seem to relate to innovation itself. To them, the importance of IMTs would be part of their culture or overall approach to innovation; their appreciation of IMTs seems to be very superficial. They all agree to recognize that IMTs are not well known, not readily identifiable and are inaccessible.

On the other hand, the lack of a clear and homogeneous view of innovation makes it difficult to relate it to the knowledge economy; the relationship between the two concepts is far from obvious and its relevance is not easy to demonstrate. In fact, managers are themselves asking for new inputs to better understand the extent and the scope of this question. Innovation in the managerial process and in information systems should be distinguished from product/services innovation and technology-based innovation, for instance.

Although success in the application of any IMT gives a measure of its ability to be accepted by industry, uncertainty and risk are, to a certain extent, inherent in the innovation management 
process. For instance, the use of creativity methods is inherently risky because the value of such methods is often not fully appreciated at the start of implementation. Therefore, the value cannot be defined in monetary terms.

Encouraging staff to disperse their acquired knowledge within the firm is a big challenge, and possibly one that can be encouraged within the knowledge-driven economy by application of technology-based tools to support this process. Some managers focus on the uncertainty of the innovation process. This inherent uncertainty in both the market and product development means that conventional methods do not meet the requirements of the knowledge-driven economy.

\section{Conclusions}

A knowledge-based economy is defined as an economy directly based on the production, distribution and use of knowledge. In such economies there is a high degree of connectivity between the agents involved, and knowledge is widely used and exploited in all manner of economic activity. We have now progressed from the knowledge-based economy to the knowledge-driven economy, emphasizing the fact that the current contribution of knowledge is very much as the dynamo of our economy.

The evolution of theories of innovation management can be explained by the increasing importance of social ingredients in the explanation of innovation, which was originally based solely on tangible forms of capital. The earlier ideas are that innovation is determined by research (technology push theory) and by unordered interaction between firms and other actors (technological networks theory). The insight is that knowledge plays a more crucial role in fostering innovation. The growing importance of knowledge as a production factor and as a determinant of innovation can be explained by the continuous accumulation of technical knowledge over time, and by the use of communications technologies that make that knowledge available very rapidly on a worldwide scale.

IMTs are critical to increasing competitiveness. IMTs can be defined as the range of tools, techniques and methodologies that support the process of innovation in firms and help them in a systematic way to meet new market challenges. Participants in the study found that the main IMTs used were project management $(82 \%)$, followed by business plan development $(67 \%)$, corporate intranets $(66 \%)$ and benchmarking $(60 \%)$. Less used IMTs included Delphi method and lateral thinking. Some $43 \%$ of the actors in the study stated that they have successfully used IMTs in their own organization. Another 32\% said that they do not use IMTs, but the techniques were known to them.

This study shows that proper application of innovation management techniques facilitates a company's ability to introduce appropriate new technologies in products or processes, as well as the necessary changes to the organization. However, most companies do not have an innovation culture that favors the introduction of change within the organization, more often there is a strong resistance from staff and sometimes from management. Also a lack of qualified personnel with experience in IMTs; most SMEs do not have the necessary in-house knowledge of IMTs and their implementation.

Few national or regional programs specifically address the promotion of IMTs, or consider business innovation and technology management techniques as a strategic aim to increase industrial competitiveness. Companies can use consulting firms to get advice in this area, but generally have no tradition of asking consultancies for their help, a practice that has resulted in a limited range of operational models. This limitation is compounded by the fragmentation of the consultancy sector working for SMEs.

Finally, the following suggestions are intended to help promote an innovation culture, to assist companies to increase their competitiveness through innovation, and to help take advantage of the opportunities of the knowledge-driven economy:

1. Set up an overall scheme together with national and regional governments to promote innovation management. The objective is to improve the know-how of actors promoting innovation management methodologies and tools within firms, in particular to SMEs. Also to promote the development of global networking among the various actors to encourage the exchange of knowledge and experience.

2. Support for well-designed awareness initiatives to enhance citizens' confidence in innovation as a means to foster competitiveness in companies and well-being in our societies. Against this backdrop and due to its importance for both consumers and firms, priority should be given to a new awareness initiative to promote 
improvements in the process of industrial design and product development.

3. Support the development of common certification systems in innovation management. Certain preparatory work (e.g. studies, consultation with national associations on various IMTs, etc.) would be necessary to define practices and standards in this area.

\section{References}

Afuah, A. (1998) Innovation Management: Strategies, Implementation, and Profits. New York: Oxford University Press.

Ahuja, G. (2000) Collaboration networks, structural holes, and innovation: a longitudinal study. Administrative Science Quarterly, 45, 3, 425-455.

Bell, D. (1974) The Comings of Post Industrial Society. London: Heineman.

Bullinger, H.J., Auernhammer, K. and Gomeringer, A. (2004) Managing innovation networks in the knowledge-driven economy. International Journal of Product Research, 42, 17, 3337-3353.

Burns, T. and Stalker, G. (1961) The Management of Innovation. London: Tavistock.

Butler, J. (1999) A practical model for technology and innovation management. Proceedings PICMET Conference, 1, 103-105, IEE.

Chesbrough, H.W. (2003) The era of open innovation. MIT Sloan Management Review, 44, 3, 35-41.

Clark, C. (1940) The Conditions of Economic Progress. New York: McMillan.

Cohen, W.M. and Levinthal, D.A. (1990) Absorptive capacity: a new perspective on learning and innovation. Administrative Science Quarterly, 35, 128-152.

Coombs, R. and Hull, R. (1998) Knowledge management practices and path dependency on innovation. Research Policy, 27, 237-253.

Coombs, R., Hull, R. and Peltu, M. (1998), Knowledge management practices for innovation: an audit tool for improvement, CRIC, working paper 6, The University of Manchester.

Cordero, R. (1991) Managing for speed to avoid product obsolescence: a survey of techniques. Journal of Product Innovation Management, 8, 283-294.

Dankbaar, B. (2003) Innovation Management in the knowledge economy; Some preliminary reflections. In Dankbaar, B. (ed.), Innovation Management in the Knowledge Economy. London: Imperial College Press, pp. 13-68.

David, P. and Foray, D. (1995) Assessing and expanding the science and technology knowledge base. STI Review, 16, 13-68.

Dogson, M. (1991) Technology, learning, technology strategy and competitive pressures. British Journal of Management, 3, 2, 132-149.

Dogson, M. (2000) The Management of Technological Innovation. Oxford: Oxford University Press.
Dosi, G. (1982) Technological paradigms and technological trajectories. Research Policy, 11, 3, 147-162.

Drucker, P.F. (1969) The Age of Discontinuity. Guidelines to our Changing Society. London: Heineman.

Drucker, P., Dyson, E., Handy, C., Saffo, P. and Senge, P.M. (1997) Looking ahead: implications of the present. Harvard Business Review, 75, 5, 18-27.

Edquist, D. (1997) Systems of Innovation. Technologies, Institutions and Organisations. London: Pinter.

European Commission, (1996) Innovation Management Tools: A review of Selected Methodologies. EIMS Publication 30. Luxembourg: DG-XIII-D.

European Commission, (2004) Innovation Management and the Knowledge - Driven Economy. Luxembourg: Directorate-general for Enterprise.

European Commission, (2005) Innovation Management Techniques (IMT Toolbox). Luxembourg: Cordis.

Frascati Manual. (2004), A summary of the Frascati manual. Main definitions and conventions for the measurement of research and experimental development (R\&D). OCDE/GD(94)84.

Freeman, C. and Soete, L. (1997) The Economics of Industrial Innovation. London: Pinter publishers.

Garcia, R. and Calantone, R. (2002) A critical look at technological innovation typology and innovativeness terminology: a literature review. Journal of Product Innovation Management, 19, 2, 110-132.

Godin, B. (2003), The Knowledge-Based Economy: Conceptual Framework or Buzzword?. Project on the History and Sociology of S\&T Statistics. Working Paper no 24.

James, W.M. (2002) Best HR practices for today's innovation management. Research Technology Management, 45, 1, 57-60.

Kipping, M. and Engwall, L. (2002) Management Consulting. Emergence and Dynamics of a Knowledge Industry. UK: Oxford University Press.

Kline, S.J. and Rosenberg, N. (1986) An Overview of Innovation. In Landau, R. and Rosenberg, N. (eds.), The Positive Sum Strategy. Harnessing Technology for Economic Growth. Washington, DC: National Academy Press, pp. 275-306.

Lengrand, L. and Chartrie, I. (1999) Business Networks and the Knowledge-Driven Economy. Brussels: European Commission.

Libutti, L. (2000) Building competitive skills in SMEs through innovation management techniques, overview of Italian experience. Journal Information Science, 26, 413-419.

Liyanage, S. and Poon, P.S. (2002) Technology and innovation management learning in the knowledge economy. The Journal of Management Development, 22, 7/8, 579-602.

Machlup, F. (1962) The Production and Distribution of Knowledge in the United States, Princeton University Press.

Martensen, A. and Dahlgaard, J.J. (1999) Integrating business excellence and innovation management: developing vision, blueprint and strategy for innova- 
tion in creative and learning organizations. Total Quality Management, 10, 4/5, 627-635.

Maskell, P. (1999) Social Capital, Innovation and Competitiveness. Oxford: Oxford University Press.

Mc Dermott, C.M. and O'Connor, G.C. (2002) Managing radical innovation: an overview of emergent strategy issues. Journal of Product Innovation Management, 19, 6, 424-438.

OECD (1996) The Knowledge-Based Economy. Paris: STI Outlook.

Oslo, Manual (2005) The Measurement of Scientific and Technological Activities. Proposed Guidelines for Collecting and Interpreting Technological Innovation Data, Paris: OECD.

Patel, P. and Pavitt, K. (1994) National innovation systems: why they are important and how they might be measured and compared. Economics of Innovation and New Technology, 3, 77-95.

Pedersen, C.R. and Dalum, B. (2004) Incremental Versus Radical Change - the case of the Digital North Denmark Program. International Schumpeter Society Conference. Italy: DRUID/IKE Group, Department of Business Studies, Aalborg University.

Phaal, R., Farrukh, C.J.P. and Probert, D.R. (2006) Technology management tools: concept, development and application. Technovation, 26, 336-344.

Popadiuk, S. and Choo, C.W. (2006) Innovation and Knowledge creation: hoe are these concepts related? International Journal Information Management, 26, pp. 302-312.

Ram, S. (1996) Validation of expert systems for innovation management: issues, methodology and empirical assessment. Journal of Product Innovation Management, 13, 53-68.

Rogers, E.M. (1983) Diffusion of Innovations. New York: The Free Press.

Schlegelmilch, B.B., Diamantopoulos, A. and Kreuz, P. (2003) Strategic innovation: the construct, its drivers and its strategic outcomes. Journal of Strategic Marketing, 11, 2, 117-132.

Schumpeter, J. (1934) The Theory of Economic Development. An inquiry into Profits, Capital, Credit, Interest, and the Business Cycle. Cambridge: Harvard University Press.

Scozzi, B. and Garavelli, C. (2005) Methods for modelling and supporting innovation processes in SMEs. European Journal Innovation Management, 8, $1,120-137$.

Thom, N. (1990) Innovation management in SMEs. Management International Review, 30, 2, 181-192.

Tushman, M.L., Anderson, P.C. and O'Reilly, C. (1997) Technological cycles, innovation streams, and ambidextrous organizations: organizational renewal through innovation streams and strategic change. In Tushman, M.L. and Anderson, P. (eds.), Managing Strategic Innovation and Change: A Collection of Readings. New York: Oxford University Press.

Urabe, K. (1988) Innovation and the Japanese management system. In Urabe, K., Child, J. and Kagono, T. (eds.), Innovation and Management, International Comparisons. Berlin: De Gruyter \& Co., pp. 3-25.

Utterback, J.M. (1994) Mastering the Dynamics of Innovation. How Companies can Seize Opportunities in the Face of Technological Change. Boston, MA: Harvard Business School Press.

Von Hippel, E. (1988) The Sources of Innovation. Oxford: Oxford University Press.

Von Hippel, E. (2005) Democratizing Innovation. Massachusetts: MIT Press.

World Bank, (1998) Knowledge for Development. World Development Report. New York: Oxford University Press.

Young, M. (1961) The Rise of the Meritocracy 1870 2033. An Essay on Education and Equality. Harmondsworth: Penguin Books.

\section{Notes}

1. These organizations and their activities have been studied by various academy schools, which have denominated them as KIBS or KISA.

2. For further information on the survey, see European Commission (2004)

Antonio Hidalgo $\mathbf{N}$ is Professor and Director of the Research Group of Innovation, IPR and Technology Policy, and Director of the Master and Doctorate Programme in MoT, Universidad Politécnica de Madrid, Spain. He received his $\mathrm{PhD}$ in industrial engineering from the Universidad Politécnica de Madrid in 1992. He has acted as expert to the European Commission as technology consultant in the European Innovation Monitoring System. His works have appeared in Production, Planning and Control Journal, Journal of Intelligent Manufacturing, Journal of Technology Transfer, International Journal of Product Development, and International Journal of Enrerpreneurship and Innovation Management. He teaches technology strategy to $\mathrm{MBA} / \mathrm{PhD}$ students and executives.

Jose Albors G is Professor of Universidad Politécnica de Valencia, Spain. He received an MBA and a $\mathrm{PhD}$ in industrial engineering from Universidad Politécnica de Madrid. He has 30 years international experience in engineering. He has published a number of articles in various journals such as Journal of Technology Transfer, Production, Planning and Control, Entrepreneurship and Regional Development, Management Research News, and European Regional Studies. His current research focuses on innovation and technology management. He teaches technology and innovation management to undergraduate and PhD students and carries out consultancy on technology management. 